\title{
Konservasi Kupu-kupu Papilio demoleus Linn. (Lepidoptera: Papilionidae) dengan Teknologi Pakan Buatan
}

\author{
Sri Nur Aminah Ngatimin ${ }^{1 *}$, Syatrawati ${ }^{2}$, Asmawati ${ }^{2}$ \\ 1Departemen Hama dan Penyakit Tumbuhan, Fakultas Pertanian Universitas Hasanuddin. \\ 2Prodi Teknologi Produksi tanaman Pangan, Politeknik Pertanian Negeri Pangkep. \\ *Email : srifirnas@gmail.com
}

ABSTRACT: The research purposes is to study and increase Papilio demoleus Linn. population by providing artificial diet. This activities providing more information about the conservation of $P$. demoleus using artificial diet. Pupae and larvae of $P$. demoleus was collected from pomelo tree at Pattunuang Resort, Maros Regency, South Sulawesi. The leaves of larvae diet taken from pomelo plantation in Bontomate'ne Village, Pangkep Regency. The experimental activities was conducted at the Pest Laboratory, Department of Plant Pests and Diseases, Faculty of Agriculture, Hasanuddin University from February to April 2019. The treatment used: $\mathrm{PO}=$ fresh pomelo leaves (control); P1 = red bean flour and pomelo leaves; P2 = red bean flour, soybean flour and pomelo leaves. The procedure used $10 P$. demoleus larvae placed in a plastic cup. Fresh pomelo leaves given in whole form and artificial diet given $5 \mathrm{~g}$ for each larva in the plastic cup. The experiments were arranged used Randomized Block Design in three treatment and ten replications. The results was showed that artificial diet P2 has a good effect on the weight gain and length of $P$. demoleus larvae when compared with $\mathrm{P} 1$. The conclusion of research: treatment with artificial diet $\mathrm{P} 2$ recommendation for conservation of $P$. demoleus.

Key words : Pomelo, Papilio demoleus, artificial diet, butterfly, red bean, soybean DOl:http:dx.doi.org/10.24259/jhm.v12i1.9981

\section{PENDAHULUAN}

Taman Nasional Bantimurung-Bulusaraung merupakan salah satu daerah tujuan wisata dan pusat keanekaragaman hayati di Sulawesi Selatan. Kawasan pegunungan karst dan hutan hujan tropis yang membentang dari Kabupaten Maros sampai Kabupaten Pangkep menjadi habitat berkembang biak ideal flora dan fauna endemik khas Sulawesi. Kupu-kupu merupakan salah satu jenis fauna Bantimurung yang sangat terkenal sampai ke manca negara. Telah lama diketahui bahwa serangga bersayap sisik ordo Lepidoptera merupakan komoditi estetik bernilai ekonomis tinggi yang diburu kolektor karena keindahan corak dan warna sayapnya.

Faktor estetik tersebut merupakan salah satu sumber penghasilan tambahan masyarakat yang bermukim di daerah Bantimurung dan sekitarnya. Kupu-kupu yang berasal dari berbagai spesies menjadi material utama pembuatan koleksi kering yang diawetkan dalam bingkai, gantungan kunci dan berbagai macam kerajinan lainnya. Bahan baku tersebut diperoleh dengan cara menangkap kupu-kupu secara langsung di alam. Kegiatan ini sangat merusak lingkungan karena kupu-kupu merupakan salah satu komponen ekosistem yang penting untuk dijaga kelestariannya (Helmiyati et al., 2010).

Salah satu spesies kupu-kupu yang dapat ditemukan di daerah Bantimurung adalah kupu-kupu jeruk/lime butterfly (Papilio demoleus L.) (Lepidoptera : Papilionidae) (Peggie dan Amir, 2006; Peggie, 2011; CABI, 2019). Serangga bersayap sisik warna warni yang dilihat oleh Alfred Russell Wallace dalam 
kunjungannya ke Bantimurung merupakan salah satu sumber keanekaragaman hayati yang berperan penting sebagai penyerbuk tanaman dan indikator kesehatan lingkungan. Secara umum larva P. demoleus hidup dengan memakan daun berbagai spesies tanaman jeruk. Di dalam kondisi kekurangan pakan, larva P. demoleus memakan tunas dan kulit batang muda yang dapat mematikan tanaman sehingga dikategorikan sebagai serangga hama yang menurunkan hasil produksi tanaman.

Berdasarkan Peraturan Pemerintah Nomor 7 Tahun 1999, terdapat empat spesies kupu-kupu yang dilindungi di Propinsi Sulawesi Selatan yakni : Troides haliphron Boisduval, Troides helena Linn., Troides hypolitus cellularis Rotschild dan Cethosia myrina. Walaupun bersayap indah, P. demoleus tidak tercantum sebagai hewan yang dilindungi di dalam Peraturan Pemerintah dan CITES (Convention on International Trade of Endangered Species) (Dishut, 2003). Namun demikian, berdasarkan kondisi saat ini di Bantimurung, populasi kupu-kupu P. demoleus juga mengalami penurunan yang sangat cepat karena adanya kerusakan habitat dan maraknya perdagangan kupu-kupu yang dilakukan oleh masyarakat dengan menangkap kupu-kupu secara langsung di dalam kawasan konservasii. Berdasarkan status populasi P. demoleus secara global, Van Swaay et al. (2014) mengemukakan bahwa P. demoleus termasuk dalam daftar IUCN Red List dan belum dilakukan tindakan konservasi. Namun demikian, upaya konservasi tetap dibutuhkan supaya populasi tersebut tetap eksis di habitat alaminya.

Teknologi pakan buatan untuk perbanyakan serangga merupakan salah satu inovasi pemeliharaan serangga dalam jumlah besar dan berkelanjutan. Pakan buatan dapat digunakan setiap saat tanpa dibatasi oleh musim dan tersedianya bahan tanaman sumber makan serangga target (Glass dan Pan, 1982; Genc dan Nation, 2004; Blanco et al., 2009). Sri et al., (2015) melaporkan bahwa pakan buatan berbahan dasar kacang merah dapat meningkatkan lama hidup larva T. helena dan menunjang keberhasilannya menjadi kupu-kupu. Rosdiana (2019) melaporkan bahwa pakan buatan untuk larva ulat sutera (Bombyx mori L.) yang berbahan dasar $44 \%$ murbei dan 32\% kacang merah memberikan hasil terbaik dalam pertambahan berat dan peningkatan kualitas kokon sutera.

Berdasarkan fakta tersebut maka tujuan penelitian adalah: mempelajari dan meningkatkan populasi kupu-kupu P. demoleus dengan memberikan pakan buatan yang mengantisipasi penurunan populasinya di alam. Kegunaan penelitian adalah: menyediakan informasi tentang teknik perbanyakan kupu-kupu $P$. demoleus dengan menggunakan pakan buatan. Diharapkan hasil penelitian yang telah dilakukan menjadi bahan informasi dalam meningkatkan populasi kupu-kupu $P$. demoleus maupun kupu-kupu spesies lainnya supaya tidak mengalami kepunahan.

\section{METODE PENELITIAN}

\subsection{Waktu dan Lokasi Penelitian}

Kegiatan dilaksanakan pada bulan Februari sampai April 2019, bertempat di Laboratorium Hama, Departemen HPT, Fakultas Pertanian Universitas Hasanuddin, Makassar. 


\subsection{Serangga Uji}

Secara umum larva $P$. demoleus memakan berbagai jenis daun tanaman jeruk. Kepompong dan larva $P$. demoleus yang digunakan dalam kegiatan dikumpulkan dari tanaman jeruk pomelo (Citrus maxima L.) yang tumbuh di pekarangan rumah masyarakat di Resort Pattunuang, Kecamatan Simbang, Kabupaten Maros. Larva disimpan dalam kotak plastik yang telah diberikan daun jeruk segar sebagai sumber makanannya. Kepompong dibungkus dengan tisu dan disimpan dalam kotak kayu. Semua fase serangga uji dibawa ke laboratorium untuk diperbanyak. Metode Pengumpulan data

\subsection{Sumber pakan P. Demoleus}

Selama masa perkembangannya, larva P. demoleus memakan daun jeruk sampai tiba fase prakepompong. Daun jeruk yang menjadi sumber pakan larva P. demoleus diambil dari kebun jeruk pomelo di Kelurahan Bontomate'ne, Kecamatan Sigeri Kabupaten Pangkep. Daun jeruk pomelo menjadi salah satu bahan baku pakan buatan selain bahan nabati lainnya yakni kacang merah dan kacang kedelai. Terdapat tiga perlakuan yang digunakan masing-masing adalah: $\mathrm{PO}=$ daun jeruk pomelo segar (kontrol); $\mathrm{P} 1=35 \%$ tepung kacang merah $+35 \%$ tumbukan daun jeruk pomelo $+30 \%$ vitamin, agar-agar, air dan bahan tambahan lainnya; P2 $=25 \%$ tepung kacang merah $+25 \%$ tepung kedelai $+25 \%$ tumbukan daun jeruk pomelo $+25 \%$ vitamin, agar-agar, air dan bahan tambahan lainnya.

Dari hasil perbanyakan P. demoleus diambil 10 ekor larva instar II. Setiap cawan plastik (diameter 8 $\mathrm{cm}$, tinggi $=6 \mathrm{~cm}$ ) bertutup kain kasa berisi seekor larva P. demoleus. Pakan larva P. demoleus diberikan daun pomelo utuh dan segar, sedangkan pakan buatan berbentuk gel sebanyak $5 \mathrm{~g}$ untuk setiap larva yang berada di dalam cawan plastik. Setiap hari cawannya dibersihkan dari sisa pakan dan kotoran larva. Saat larva P. demoleus menjelang membentuk kepompong (ditandai dengan adanya muntahan sisa makanan dan larva berhenti makan), larva dipindahkan ke toples plastik bertutup kain kasa berisi sebatang ranting kayu yang digunakan untuk tempat memintal kepompong. Percobaan disusun dalam Rancangan Acak Kelompok dengan tiga perlakuan dan sepuluh ulangan

\subsection{Analisis DataPenutupan Lahan}

Data yang diperoleh dari hasil perbanyakan kupu-kupu dengan menggunakan makanan buatan ditabulasi kemudian dianalisis dengan menggunakan ANOVA. Jika terdapat perbedaan yang nyata diuji dengan Duncan Multiple Range Test $a=0.05$.

\section{HASIL DAN PEMBAHASAN}

\subsection{Perkembangan Larva P. demoleus pada Tiga Macam Pakan}

Berdasarkan hasil pengamatan terdapat perbedaan berat tubuh larva $P$. demoleus yang diberikan tiga macam pakan yang disajikan pada Tabel 1 . 
Tabel 1. Berat tubuh larva $P$. demoleus pada tiga macam pakan

\begin{tabular}{|c|c|c|c|c|}
\hline \multirow{2}{*}{ Perlakuan } & \multicolumn{4}{|c|}{ Berat Tubuh Larva P. demoleus (g) } \\
\cline { 2 - 5 } & II & III & IV & V \\
\hline P0 & $3.69 \pm 0.66^{\mathrm{a}}$ & $3.94 \pm 0.19^{\mathrm{a}}$ & $3.69 \pm 1.30^{\mathrm{a}}$ & $3.69 \pm 1.30^{\mathrm{a}}$ \\
\hline P1 & $1.44 \pm 0.74^{\mathrm{c}}$ & $0.55 \pm 0.88^{\mathrm{c}}$ & $0.41 \pm 0.87^{\mathrm{c}}$ & $0.41 \pm 0.87^{\mathrm{c}}$ \\
\hline P2 & $2.64 \pm 0.24^{\mathrm{b}}$ & $2.07 \pm 1.43^{\mathrm{b}}$ & $2.15 \pm 1.49^{\mathrm{b}}$ & $2.15 \pm 1.49^{\mathrm{b}}$ \\
\hline
\end{tabular}

(P0 = kontrol; P1 = tepung kacang merah + daun jeruk pomelo; $\mathrm{P} 2$ = tepung kacang

merah+ tepung kedelai + daun jeruk pomelo)

Perlakuan P0 memberikan hasil tertinggi dalam pertambahan berat tubuh larva $P$. demoleus. Selain $\mathrm{P} 0$, pertambahan berat tubuh larva $P$. demoleus tertinggi selanjutnya ditunjukkan oleh perlakuan $\mathrm{P} 2$ yang mengalami peningkatan berat tubuh sejak instar II ( $0.74 \mathrm{~g})$ sampai dengan instar IV $(0.87 \mathrm{~g})$. Selain berat tubuh, maka panjang tubuh larva $P$. demoleus juga dipengaruhi oleh pemberian tiga macam pakan (Tabel 2).

Tabel 2. Panjang tubuh larva $P$. demoleus pada tiga macam pakan

\begin{tabular}{|c|c|c|c|c|}
\hline \multirow{2}{*}{ Perlakuan } & \multicolumn{4}{|c|}{ Panjang Tubuh Larva P. demoleus (cm) } \\
\cline { 2 - 5 } & II & III & IV & V \\
\hline P0 & $2.20 \pm 0.29^{\mathrm{a}}$ & $3.14 \pm 1.17^{\mathrm{a}}$ & $3.19 \pm 1.19^{\mathrm{a}}$ & $3.35 \pm 0.47^{\mathrm{a}}$ \\
\hline P1 & $1.95 \pm 0.21^{\mathrm{c}}$ & $0.77 \pm 1.25^{\mathrm{c}}$ & $0.56 \pm 1.91^{\mathrm{c}}$ & $0.57 \pm 1.2^{\mathrm{c}}$ \\
\hline P2 & $2.08 \pm 0.24^{\mathrm{b}}$ & $2.31 \pm 1.66^{\mathrm{b}}$ & $2.42 \pm 1.72^{\mathrm{b}}$ & $2.40 \pm 1.71^{\mathrm{b}}$ \\
\hline
\end{tabular}

(P0 = kontrol; $\mathrm{P} 1=$ tepung kacang merah + daun jeruk pomelo; $\mathrm{P} 2$ = tepung kacang merah+ tepung kedelai + daun jeruk pomelo)

Perlakuan P0 berupa daun pomelo segar memberikan hasil tertinggi dalam pertambahan panjang tubuh larva $P$. demoleus. Selain $\mathrm{P0}$, pertambahan panjang tubuh larva $P$. demoleus tertinggi selanjutnya ditunjukkan oleh perlakuan P2 pada larva instar II $(0.24 \mathrm{~cm})$ sampai dengan instar IV $(1.72 \mathrm{~cm})$. Larva $P$. demoleus instar $\mathrm{V}$ mengalami penyusutan panjang badan karena serangga tersebut memasuki tahap pra kepompong. Fase ini ditandai dengan larva tidak bergerak, mengeluarkan muntahan warna hitam lalu berhenti makan, tubuhnya terlihat lebih transparan, memendek dan adanya gumpalan kulit lama di ujung abdomen. Sri et al. (2015) melaporkan bahwa menjelang fase pra kepompong, larva instar akhir akan memuntahkan makanan yang tidak tercerna dengan tujuan mengurangi isi abdomen saat menjadi kepompong. Adanya pasokan pakan selama proses pertumbuhan menyebabkan terjadinya peningkatan proses metabolisme tubuh serangga karena bekerjanya organ internal secara aktif, termasuk hemolymph yang mengangkut nutrisi ke seluruh tubuh serangga. Pandey et al., (2011) melaporkan bahwa beberapa spesies tanaman mengeluarkan senyawa flavonoid dan tannin yang bersifat sebagai anti feedant pada serangga fitofag. Hal ini merupakan pertahanan tanaman secara kimiawi terhadap serangan serangga. Senyawa metabolit sekunder yang dihasilkan oleh tanaman dapat menjadi racun yang mematikan pada beberapa jenis serangga tertentu. Selain pertahanan kimiawi terdapat pula physical barrier berupa adanya bulu kasar pada daun, duri pada batang dan lain-lain. 
Berdasarkan hasil pengamatan visual diperoleh jumlah nisbah kelamin kupu-kupu $P$. demoleus yang berhasil menetas dari kepompong (Tabel 3).

Tabel 3. Nisbah kelamin kupu-kupu P. demoleus dari tiga macam pakan

\begin{tabular}{|c|c|c|c|}
\hline \multirow{2}{*}{ Perlakuan } & \multicolumn{2}{|c|}{ Nisbah Kelamin } & \multirow{2}{*}{ Total (ekor) } \\
\cline { 2 - 3 } & Jantan & Betina & 8 \\
\hline P0 & 5 & 3 & 1 \\
\hline P1 & 1 & - & 3 \\
\hline P2 & 2 & 1 & \\
\hline
\end{tabular}

(P0 = kontrol; P1 = tepung kacang merah + daun jeruk pomelo; $\mathrm{P} 2$ = tepung kacang merah + tepung kedelai + daun jeruk pomelo)

Berdasarkan hasil pada Tabel 3 dapat dilihat bahwa perlakuan P0 memberikan hasil tertinggi menghasilkan individu kupu-kupu P. demoleus (8 ekor), diikuti oleh P2 (3 ekor) dan P1 (1 ekor). Nisbah kelamin tertinggi berupa kupu-kupu $P$. demoleus betina dihasilkan oleh perlakuan P0 ( 3 ekor), perlakuan P2 (1 ekor) dan P1 tidak menghasilkan kupu-kupu betina. Lama stadium larva $P$. demoleus sampai menjadi kupu-kupu yang dibiakkan pada perlakuan P0 sekitar 21 hari, P1 sekitar 14 hari dan P2 sekitar 19 hari pada suhu lingkungan sekitar $22-25^{\circ} \mathrm{C}$. Helmiyati et al. (2010) melaporkan bahwa siklus hidup $P$. demoleus yang dibiakkan secara alami pada tanaman jeruk pomelo berkisar $22-24$ hari pada kondisi suhu lingkungan $26-28^{\circ} \mathrm{C}$ dengan kelembaban nisbi $67-84 \%$. Siklus hidup $P$. demoleus yang singkat pada perlakuan P1 terjadi karena nutrisi pakannya tidak dapat mendukung perkembangan larva secara optimal sehingga pertumbuhannya mengalami kondisi prematur. Taylor et al. (1981) mengemukakan bahwa nutrisi yang tidak sesuai akan menghasilkan serangga prematur dengan kondisi yang rentan (gampang mati).

Astuti (1992) melaporkan bahwa pemberian linseed oil pada pakan buatan kupu-kupu dapat meningkatkan keberhasilan larva $P$. demoleus menjadi kupu-kupu. Secara umum daun jeruk (Citrus spp.) mengandung minyak atsiri dan sitosterol yang sangat dibutuhkan dalam perkembangan serangga. Konsentrasi sitosterol yang terdapat dalam daun jeruk berkontribusi penting di dalam perkembangan larva fitofag khususnya dalam keberhasilan menjadi serangga dewasa (kupu-kupu). Pandey et al. (2012) mengemukakan bahwa komponen kimiawi tanaman seperti : alkaloid, fenol dan flavonoid memainkan peranan yang sangat penting di dalam metabolisme serangga pradewasa menuju ke tahap dewasa.

Secara umum ketahanan hidup larva $P$. demoleus menunjukkan adaptasi terbaik pada perlakuan P0 (daun jeruk pomelo). Berdasarkan hasil penelitian dapat dilihat bahwa perlakuan pakan buatan P2 (tepung kacang merah + tepung kedelai + daun jeruk pomelo) memberikan hasil terbaik dalam pertambahan berat badan, panjang tubuh dan keberhasilan menjadi kupu-kupu bila dibandingkan dengan P1 (tepung kacang merah + daun jeruk pomelo). Blanco et al. (2009) mengemukakan bahwa kedelai yang digunakan sebagai bahan baku dalam pakan buatan larva Heliothis virescens mempunyai kandungan protein nabati sebanyak $2.8 \mathrm{~g}$ per $100 \mathrm{~g}$ bahan kering. Kedelai mengandung asam amino yang berperan penting dalam mengatur dan menstabilkan kerja sel yang sedang tumbuh dengan cara meregenerasi sel yang rusak. 
Pakan buatan serangga dibuat untuk memudahkan perbanyakan kupu-kupu dalam jumlah besar. Hal ini dapat mengantisipasi kekurangan pakan alami yang berasal dari alam yang kualitas dan kuantitasnya tidak dapat dipastikan, contohnya daun jeruk yang dibutuhkan oleh larva $P$. demoleus sebagai sumber pakannya.

Teknologi pakan buatan dapat menjadi alternatif perbanyakan spesies kupu-kupu yang berada dalam status endangered species di alam. Saat ini konservasi dengan menggunakan pakan buatan dapat dilakukan secara eks-situ. Konservasi eks-situ mempunyai dua tujuan utama yakni : konservasi secara ekonomi dan konservasi genetik (Dishut, 2003). Berdasarkan hasil yang disajikan pada Tabel 3 terlihat bahwa hasil penelitian ini memberikan harapan dilakukannya konservasi $P$. demoleus secara ekonomi. Larva $P$. demoleus yang diberikan pakan buatan mampu menetas sebagai kupu-kupu. Serangga hasil perbanyakan ini dapat dijual secara legal, kualitasnya terjamin dan mudah diaplikasikan sehingga mampu meningkatkan taraf hidup masyarakat tanpa melakukan penangkapan kupu-kupu di habitatnya. Dipandang perlu dilakukan penelitian lanjutan untuk menguji kualitas pakan buatan dengan tujuan konservasi genetik karena aplikasi pakan buatan pada larva $P$. demoleus belum menghasilkan kupu-kupu betina. Kupu-kupu betina merupakan aset yang sangat penting dalam konservasi genetik karena serangga betina merupakan kunci eksistensi suatu spesies di alam.

\section{KESIMPULAN}

Berdasarkan hasil penelitian ditemukan bahwa pakan buatan P2 yang mengandung daun jeruk pomelo, tepung kacang merah dan tepung kedelai dapat digunakan untuk perbanyakan dan mendukung konservasi $P$. demoleus.

\section{DAFTAR PUSTAKA}

Astuti, D., 1992. Pakan buatan larva kupu-kupu Papilio demoleus. Puslitbang Biologi LIPI Cibinong Bogor, pp. 366-372.

Blanco, C. A., Portilla, M., Abel, C. A., Winters, H., Ford, R., and Street, D., 2009. Soybean flour and wheat germ proportions in artificial diet and their effect on the growth rates of the tobacco budworm, Heliothis virescens. Journal of Insect Science, 9 (59), 1-9.

CABI, 2019. Papilio demoleus (chequered swallowtail). Invasive Species Compendium. https://www.cabi.org/isc/datasheet/38758 (diakses tanggal 1 Mei 2020).

Dishut, 2003. Informasi Kawasan Konservasi : Potensi Kupu-kupu di Wilayah Kerja Balai KSDA Sulawesi Selatan. Departemen Kehutanan Dirjen Perlindungan Hutan dan Konservasi Alam BKSDA Sulawesi Selatan.

Genc, H., and Nation, J. L., 2004. An artificial diet for the butterfly Phyciodes phaon (Lepidoptera: Nymphalidae). Florida Entomologist, 87 (2), 194-198. 
Glass, H. W., and Pan, M. L., 1982. Laboratory rearing of Monarch butterflies (Lepidoptera: Danaiidae) using an artificial diet. Annals of The Entomological Society of America, 76: 475-476.

Helmiyati, Dahelmi dan Diana, S. Y., 2010. Lama stadia pradewasa beberapa jenis kupu-kupu Papilionidae pada tanaman inang jeruk Bali (Citrus maxima Merr.). Jurnal Konservasi Hayati, 6 (2), 9-19.

Pandey, J. P., Tiwari, R. K., and Chaubey, A. K., 2011. Effect of repeated haemolymph withdrawls on haemocyte count in lemon butterfly, Papilio demoleus L. Indian J. Exp. Biol., 41: 1436-1445.

Pandey, S., Pandey, J.P., and Tiwari, R. K., 2012. Effect of some botanicals on hemocytes and molting of Papilio demoleus larvae. Journal of Entomology, 3 (1), 23-31.

Peggie, D., and Amir, M., 2006. Practical Guide to The Butterflies of Bogor Botanic Garden. Pusat Penelitian Biologi, LIPI Cibinong, Indonesia.

Peggie, D., 2011. Precious and Protected Indonesian Butterfly. Puslit Biologi LIPI and Nagao Natural Environment Foundation.

Rosdiana, 2019. Pengaruh pakan buatan kedelai (Glycine max L.) dan kacang merah (Phaseolus vulgaris L.) terhadap pertumbuhan larva dan produksi kokon ulat sutera (Bombyx mori L.). Jurnal Hutan dan Masyarakat, 11(2): 79-91.

Sri, N. A. N., Saranga, A. P., Agus, N., Achmad, A., and Ridwan, I., 2014. Two artificial diet formulations for Troides helena Linne larvae (Lepidoptera: Papilionidae) in Bantimurung-Bulusaraung National Park, South Sulawesi. International Journal of Scientific and Technology Research, 3(7): 170-173.

Taylor, O. R., Grula, J. W., and Hayes, J. I., 1981. Artificial diets and continuous rearing methods for sulphur butterflies Colias eurytheme and Colias philodice (Pieridae). Journal of The Lepidopterist Society, 35(4): 281-289.

Van Swaay, C., Wynhoff, I., Wiemers, M., Katbeh-Bader, A., Power, A., Benyamini,

D., Tzirkalli, E., Balletto, E., Monteiro, E., Karaçetin, E., Franeta, F., Pe'er, G., Welch, H., Thompson, K., Pamperis, L., Dapporto, L., Šašić, M., López Munguira, M., Micevski, N., Dupont, P., Garcia-Pereira, P., Moulai, R., Caruana, R., Verovnik, R., Bonelli, S., and Beshkov, S., 2014. Papilio demoleus. The IUCN Red List of Threatened Species 2014: e.T62148774A62153282. https://www.iucnredlist.org/species/62148774/62153282 (diakses tanggal 30 Juli 2020). 